ORIGINAL ARTICLE

\title{
Prevalence of various pathogens isolated from urine cultures causing urinary tract infections in Bakhtawar Amin Trust Hospital, Multan
}

MUHAMMAD BILAL PASHA ${ }^{1}$, ZERTAJ KASHIF ${ }^{2}$, KANWAR SAJID $^{3}$, SEHAR BASHIR ${ }^{4}$, SEHAR SHAMSHAD ALI ${ }^{5}$, IREM ZOYA TARIQ ${ }^{6}$, AAMIR ALI KHAN 7 , SABA SHAMIM ${ }^{8}$

${ }^{1,4}$ Assistant Professor, Department of Pathology, Bakhtawar Amin Medical \& Dental College, Multan

${ }^{2,3}$ Associate Professor, Department of Pathology, Bakhtawar Amin Medical \& Dental College, Multan

${ }^{5}$ Senior Demonstrator Pathology, Bakhtawar Amin Medical \& Dental College, Multan

${ }^{6}$ Demonstrator Pathology, Bakhtawar Amin Medical \& Dental College, Multan

${ }^{7}$ Professor of Pathology, Bakhtawar Amin Medical \& Dental College, Multan

${ }^{8}$ Assistant Professor of IMBB Department, University of Lahore

Correspondence to: Dr. Zertaj Kashif, Email: zkashif786@icloud.com, Cell: 03146121201

\begin{abstract}
Objective: This study is conducted to ascertain the microbial agents along with their prevalence leading to urinary tract infections in patients admitted in Bakhtawar Amin Hospital, Multan with manifestations of urinary tract infections.

Design: Descriptive observational study

Place and duration of study: Department of Microbiology Bakhtawar Amin Medical \& Dental College \& Hospital, Multan from January 2021 to July 2021.

Material and Methods: A total of 220 positive urine cultures were analyzed in this study extended for six months. All the appropriate details like age, gender, major presenting complaints, history of catheterization etc were noted. All the isolated urinary pathogens were recorded along with their frequency and percentages.

Results: Out of these 220 patients with positive urine cultures, majority (63.6\%) were male. Gram negative bacteria (E. Coli) constitute the major bulk of urinary pathogens followed by Candida.

Conclusion: Urinary tract infections were commonly seen in men in our region. E. Coli was the most frequently encountered bacteria. A large number of Candida species were segregated in immunocompromised critically ill ICU admitted patients.
\end{abstract}

Keywords: Urinary tract infection, culture, pathogens, E.Coli, Candida.

\section{INTRODUCTION}

All over the world, the major bulk of infection related diseases received in health care units, is of urinary tract infection (1); seen inalmost every age group and in both men and women. Recurrent UTI is mostly encountered in sexually active women and almost half of the population of women is definitely affected at least once in their lives. (2, $3,4) \mathrm{UTI}$ is a designation given todiverse clinical states varying from symptomless presence of microbes in the urine to grave renal inflammation consequently leading to septicemia. (5) Urinary tract infections account for a large proportion of hospital acquired infections and mostly related to urinary catheterization. Various factors such as age, sex, sexual activity, pregnancy, prostatic enlargement, infrequent micturition, bed wetting at night during sleep and faulty toilet habits are potential etiologic factors leading to UTI along with frequent and extended usage of anti microbials leading to replacement of normal beneficial urine flora by pathogenic organisms. $(6,7)$

\section{MATERIAL AND METHODS}

The research is conducted in Microbiology Department of Bakhtawar Amin hospital. Positive culture reports of all the urine samples sent to microbiology section of hospital laboratory were included. All the relevant data like age, sex, clinical signs and symptoms and indication of culture and sensitivity are noted along with microbiologic culture report. The particulars were obtained from medical track record, microbiologic culture request form and culture report registers. Percentage and proportions were calculated for all the variables. Relevant tables and charts were computed.

\section{RESULTS}

During the last seven months, a total of 220 positive urine cultures were reported in the microbiology department. The mean age was 65 years (ranging from 6 months to 75 years). Out of these 220 patients 140 (63.6\%) were male. The major presenting complaints were fever, dysuria (burning micturition) and urgency.In majority of these positive urine cultures, the urinary tract infection was related to catheterization and the sample was obtained from indwelling catheters especially in men.Major bulk of urinary pathogens in our study was formed by gram negative bacteria.

Escherichia coli was the most frequently found gram negative UTI causing bacteria followed by Candida in our study.

Table: Percentage and proportions of various pathogens found on urine culture

\begin{tabular}{|l|l|l|}
\hline Organism & Numbers & Percentage (\%) \\
\hline E. Coli & 110 & 50 \\
\hline Candida species & 29 & 13.2 \\
\hline Pseudomonas species & 25 & 11.4 \\
\hline Klebsiella species & 15 & 6.8 \\
\hline Enterobacter & 16 & 7.3 \\
\hline Proteus species & 10 & 4.5 \\
\hline Staph. saprophyticus & 15 & 6.8 \\
\hline Total & 220 & 100 \\
\hline
\end{tabular}


Distribution of cases on the basis of gender

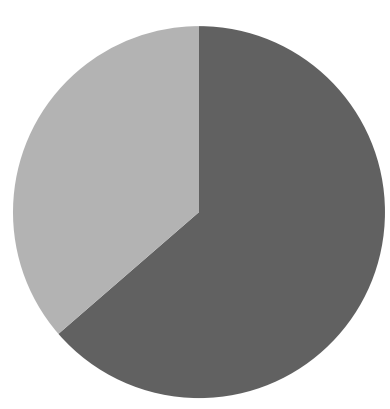

Males (63.6\%) Females (36.4\%)

\section{DISCUSSION}

This study is conducted to ascertain the microbial agents responsible for urinary tract infections in Bakhtawar Amin Hospital, Multan. The mean age of patients who develop urinary tract infections in our study was 65 years in accordance with the study by Silver SA et al where they found mean age of 68 years. (8)

Out of these 220 patients with positive urine cultures, $140(63.6 \%)$ patients were males, comparable to studies conducted by Silver SA et al, Lopes HV and Head KA. The application of instruments especially indwelling catheters and the development of ailments related to prostate are the elements involved in the rising frequency of UTI in men. In our study a vast majority of positive urinary tract infections were related to catheterization and the samples were taken from indwelling catheters. $(8,9,10)$

The most common presenting complaints associated with urinary tract infections in our study were fever, buning micturition and urgency. Similar mode of presentations was seen in several other studies. $(11,12,13)$

Most pathogens in our study were bacteria belonging to gram negative family. This is comparable to studies by Ullah A and Seifu WD. $(6,14)$

$\mathrm{E}$ coli was the commonest bacteria responsible for urinary tract infection in our study comparable to many other studies $(12,15,16,17,18,19)$ followed by Candida species.

The reason of high percentage of Candida in our study is that most of these patients were seriously ill and hospitalized in ICU and were immunocompromised. Several studies proved such links. $(20,21,22)$

\section{CONCLUSION}

Urinary tract infections were more frequently found in men in this region. $E$ Coli was the commonest pathogen. However, Candida species were isolated in a large number of immunocompromised seriously ill patients admitted in intensive care unit of the hospital.

\section{REFERENCES}

1. Medina M, Castillo-Pino E. An introduction to the epidemiology and burden of urinary tract infections. Therapeutic advances in urology. 2019 Mar;11:1756287219832172.

2. Behzadi $P$, Carevic $B$, editors. Microbiology of Urinary Tract Infections: Microbial Agents and Predisposing Factors. BoDBooks on Demand; 2019 Feb 13.
3. Dibua UM, Onyemerela IS, Nweze El. Frequency, urinalysis and susceptibility profile of pathogens causing urinary tract infections in Enugu State, southeast Nigeria. Revista do Instituto de Medicina Tropical de São Paulo. 2014 Jan;56:55-9.

4. Peinado IDT, Mediavilla-Gradolph MC, Tormo-Palop N, PalopBorrás B. Microbiological diagnosis of urinary tract infections. EnfermInfeccMicrobiolClin. $2015 \mathrm{Jul}$; 33:34-9.

5. Kumar V, George A, Viswanathakumar M. Study of clinical profile and risk factors associated with febrile urinary tract infection in preschool children. International Journal of Contemporary Pediatrics. 2016 Jan;3(1):243-6.

6. Seifu WD, Gebissa AD. Prevalence and antibiotic susceptibility of Uropathogens from cases of urinary tract infections (UTI) in Shashemene referral hospital, Ethiopia. BMC infectious diseases. 2018 Dec;18(1):1-9.

7. Emiru T, Beyene G, Tsegaye W, Melaku S. Associated risk factors of urinary tract infection among pregnant women at FelegeHiwot Referral Hospital, Bahir Dar, North West Ethiopia. BMC research notes. 2013 Dec;6(1):1-6.

8. Silver SA, Baillie L, Simor AE. Positive urine cultures: a major cause of inappropriate antimicrobial use in hospitals?. Canadian Journal of Infectious Diseases and Medical Microbiology. 2009 Oct;20(4):107-11.

9. Lopes HV, Tavares W (2004) ProjetoDiretrizesAssociaçãoMédicaBrasileira (AMB) e Conselho Federal de Medicina (CFM); SociedadeBrasileira de Infectologia e SociedadeBrasileira de Urologia. Infecções do TratoUrinário: Diagnóstico

10. Head KA (2008) Natural approaches to prevention and treatment of infections of the lower urinary tract. Altern Med Rev 13: 227244)

11. Beahm NP, Nicolle LE, Bursey A, Smyth DJ, Tsuyuki RT. The assessment and management of urinary tract infections in adults: guidelines for pharmacists. Canadian Pharmacists Journal/Revue des Pharmaciens du Canada. 2017 Sep;150(5):298-305.

12. Thoureen T, Scott S, Best J, LoVecchio F. Urinary tract infection. Monograph. Retrieved. 2015 Mar 1.

13. Doern CD, Richardson SE. Diagnosis of urinary tract infections in children. Journal of clinical microbiology. 2016 Sep;54(9):2233-42.

14. Ullah A, Shah SR, Almugadam BS, Sadiqui S. Prevalence of symptomatic urinary tract infections and antimicrobial susceptibility patterns of isolated uropathogens in kohat region of Pakistan. MOJ Biol Med. 2018;3(4):85-9.

15. Giri A, Kafle R, Singh GK, Niraula N. Prevalence of Escherichia Coli in Urinary Tract Infection of Children Aged 1-15 Years in a Medical College of Eastern Nepal. JNMA: Journal of the Nepal Medical Association. 2020 Jan;58(221):11.

16. e Silva MF, de Sena FC, Agostinho F, Medeiros KK, Miguel CB, Rodrigues WF. Urinary tract infection related to hospitalized patients: A Review. Archive of Urological Research. 2017 Oct 5;1(1):001-4.

17. Vranic SM, Zatric N, Rebic V, Aljicevic M, Abdulzaimovic A. The most frequent isolates from outpatients with urinary tract infection. Materia socio-medica. 2017 Mar;29(1):17.

18. Shaifali I, Gupta U, Mahmood SE, Ahmed J. Antibiotic susceptibility patterns of urinary pathogens in female outpatients. North American journal of medical sciences. 2012 Apr;4(4):163.

19. Aamir AH, Raja UY, Asghar A, Mahar SA, Ghaffar T, Ahmed I, Qureshi FM, Zafar J, Hasan MI, Riaz A, Raza SA. Asymptomatic urinary tract infections and associated risk factors in Pakistani Muslim type 2 diabetic patients. BMC Infectious Diseases. 2021 Dec;21(1):1-6.

20. Cox G M, Kauffman C A. Candida infections of the bladder and kidneys. Sep 09, 2020.

21. Behzadi P, Behzadi E, Yazdanbod H, Aghapour R, Cheshmeh MA, Omran DS. Urinary tract infections associated with Candida albicans. Maedica. 2010 Dec;5(4):277.

22. Dias V. Candida species in the urinary tract: is it a fungal infection or not? 17 Feb 2020 